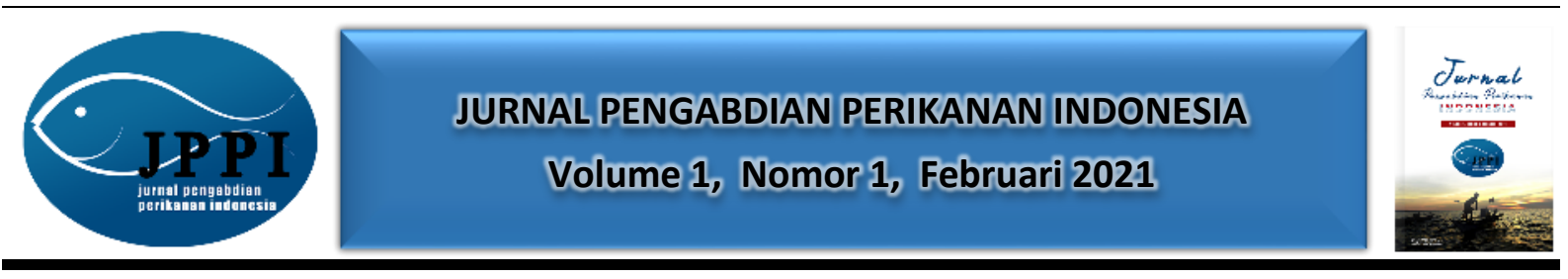

\title{
PELATIHAN PENGOLAHAN PRODUK PERIKANAN BAGI WANITA PESISIR DI DESA MERTAK KECAMATAN PUJUT KABUPATEN LOMBOK TENGAH
}

\author{
Nurliah Buhari, Saptono Waspodo, Ayu Adhita Damayanti, Ibadur Rahman, \\ Mahardika Rizki Himawan
}

\author{
Program Studi IImu Kelautan, Universitas Mataram
}

Alamat korespondensi : nurliah.buhari@unram.ac.id

(Tanggal Submission: 3 Desember 2020, Tanggal Accepted : 2 Februari 2021)

\begin{abstract}
Keyword: Abstrak:
olahan ikan, Desa Mertak adalah salah satu dari 6 desa penyangga Kawasan Ekonomi khusus (KEK) pemanfaatan Mandalika. Secara geografis, Desa Mertak berbatasan langsung dengan dua teluk yaitu Teluk sumberdaya Awang dan Teluk Bumbang. Kedua teluk tersebut, merupakan habitat benih lobster dan ikanlaut, desa ikan karang. Selain itu, sebelah Selatan dari kedua teluk tersebut adalah perairan Samudera mertak Hindia yang merupakan daerah penangkapan untuk ikan-ikan pelagis. Kegiatan pengabdian kepada masyarakat dilakukan untuk meningkatkan kapasitas wanita pesisir dalam memanfaatkan sumberdaya laut sekaligus memberikan keterampilan yang dapat digunakan untuk memanfaatkan peluang dari pengembangan KEK Mandalika sebagai destinasi pariwisata super prioritas. Kegiatan dilakukan melalui 3 tahap yaitu persiapan, pelaksanaan dan evaluasi. Tahap persiapan dilakukan dengan melakukan kordinasi dengan pemerintah desa dan melakukan diskusi dengan calon peserta terkait dengan waktu pelaksanaan dan lokasi pelatihan. Tahap pelaksanaan yaitu pelaksanaan pelatihan terdiri dari pemaparan materi dan praktek pengolahan produk perikanan secara partisipatif. Tahap evaluasi dilakukan melalui wawancara dengan peserta setelah pelatihan selesai dilaksanakan. Peserta terlihat antusias dan aktif berpartisipasi selama pelatihan dilakukan. Para peserta merasa puas dengan produk yang dihasilkan baik dari segi rasa maupun tampilan. Peserta juga merasa mampu untuk membuat kedua produk tersebut secara mandiri. Namun demikian, wawancara setelah 2 bulan pelaksanaan pelatihan, para peserta belum pernah membuat kembali produk tersebut.
\end{abstract}

Panduan Sitasi (APPA $7^{\text {th }}$ edition) :

Buhari, N., Waspodo, S., Damayanti, A.A., Rahman, I., \& Himawan, M.R., (2021). Pelatihan Pengolahan Produk Perikanan Bagi Wanita Pesisir Di Desa Mertak Kecamatan Pujut Kabupaten Lombok Tengah. Jurnal Pengabdian Perikanan Indonesia, 1 (1), 29-35. http://doi.org/ 10.29303/jppi.v1i1.40

\section{PENDAHULUAN}

Kabupaten Lombok Tengah Provinsi Nusa Tenggara Barat mempunyai luas wilayah sebesar $1.208,39 \mathrm{~km}^{2}$ dengan topografi yang beragam (BPS Lombok Tengah, 2019). Bagian utara merupakan daerah dataran tinggi yang merupakan areal kaki Gunung Rinjani. Bagian tengah merupakan daerah dataran rendah dan pada bagian Selatan merupakan wilayah pesisir yang berbatasan langsung dengan Samudera Hindia. 
Desa Mertak merupakan salah satu desa di Kecamatan Pujut Kabupaten Lombok Tengah yang berbatasan langsung dengan dua teluk yaitu Teluk Awang dan Teluk Bumbang. Kedua teluk tersebut adalah habitat benih lobster (Priyambodo, Jones and Sammut, 2020) dan juga merupakan habitat dari berbagai jenis ikan karang (Faizah, Sadiyah and Aisyah, 2020). Di Desa Mertak juga terdapat Pelabuhan Perikanan Nusantara (PPN) Teluk Awang yang mendaratkan ikan pelagis yang merupakan hasil tangkapan di WPP 573.

Selain memiliki sumberdaya perikanan yang tinggi, Desa Mertak adalah salah satu desa penyangga Kawasan Ekonomi Khusus (KEK) Mandalika (Amir, Sukarno and Fauzi, 2020). KEK Mandalika akan dikembangkan sebagai kawasan destinasi wisata super prioritas dengan konsep sportainment (ITDC, 2020). Kegiatan wisata dapat mempengaruhi perkembangan sector-sektor lainnya yang pada akhirnya akan mempunyai dampak langsung dan tidak langsung serta dampak lanjutan terhadap ekonomi masyarakat setempat (Ikhsan, Mardiana and Setiawan, 2016; Aji, Pramono and Rahmi, 2018).

Namun demikian, kesiapan masyarakat sebagian besar desa-desa wisata di Kabupaten Lombok Tengah termasuk Desa Mertak dinilai masih kurang (Amir, Sukarno and Fauzi, 2020). Tingkat pemahaman masyarakat mengenai kepariwisataan masih rendah. Begitu juga dengan keterampilan yang dimiliki masih terbatas sehingga partisipasi mereka dalam pengelolaan pariwisata menjadi rendah.

Oleh sebab itu maka kegiatan pengabdian kepada masyarakat sangat diperlukan untuk meningkatkan kapasitas masyarakat Desa Mertak. Melalui kegiatan pelatihan pengolahan produk perikanan diharapkan dapat menambah keterampilan wanita dalam membuat produk olahan ikan baik untuk konsumsi keluarga maupun untuk dibuat sebagai mata pencaharian alternatif dalam rangka memanfaatkan peluang dari adanya KEK Mandalika.

\section{METODE KEGIATAN}

Kegiatan pengabdian ini dilaksanakan pada bulan September - Nopember 2020 di Desa Mertak, Kecamatan Pujut Kabupaten Lombok Tengah (Gambar 1). Jarak Desa Mertak dari Kota Mataram sekitar $50 \mathrm{~km}$

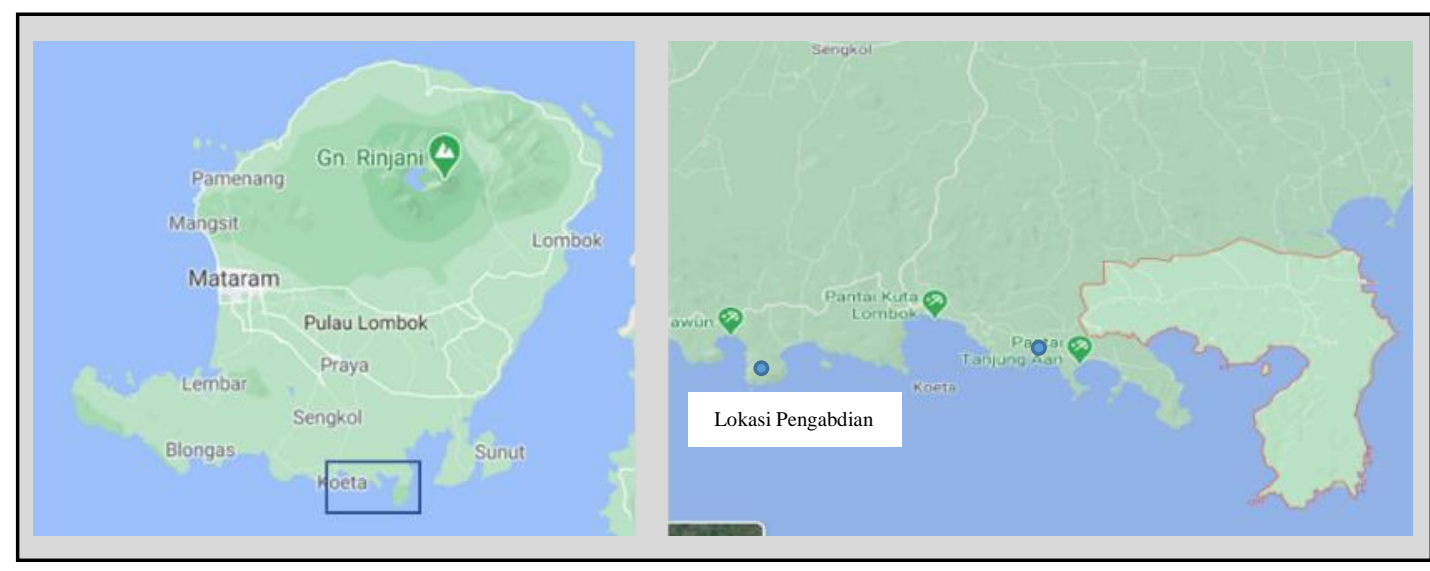

Gambar 1. Lokasi Kegiatan Pengabdian di Desa Mertak Kecamatan Pujut

Kegiatan pengabdian kepada masyarakat dilakukan melalui 3 tahap. Tahap pertama adalah persiapan yang terdiri dari persiapan calon peserta, tempat pelatihan, dan jenis produk yang akan dilatihkan. Tahap ini dilakukan dengan cara berkordinasi dengan pemerintah Desa Mertak. Tahap kedua adalah pelaksanaan kegiatan yaitu pelatihan pembuatan kerupuk ikan yang dilakukan dengan 
melibatkan secaara langsung peserta. Tahap ketiga adalah evaluasi kegiatan yang dimaksudkan untuk mengetahui tingkat pemahaman dan keterampilan peserta membuat olahan ikan dan tindak lanjut dari peserta melalui wawancara.

\section{HASIL DAN PEMBAHASAN}

Hasil pelaksanaan kegiatan pengabdian kepada masyarakat di Desa mertak dijelaskan sebagai berikut:

\section{Tahap Persiapan}

Kegiatan persiapan yang dilakukan meliputi persiapan peserta pelatihan, tempat dan waktu pelatihan, jenis produk yang akan dipraktekkan, dan ketersediaan bahan dan alat. Kegiatan tersebut dilakukan dengan cara berkoordinasi langsung dengan pemerintah Desa Mertak yang diwakili oleh sekretaris desa karena lebih mengenal warga dan lokasi disbanding dengan Pjs Kades Mertak yang dijabat oleh pegawai kecamatan.

Sekretaris desa memfasilitasi pertemuan dengan ibu-ibu rumah tangga calon peserta pelatihan (Gambar 2). Melalui diskusi diketahui bahwa telah terbentuk kelompok wanita Desa Mertak yang anggotanya adalah ibu-ibu rumah tangga yang berasal dari 24 dusun yang berada dalam wilayah administrasi Desa Mertak. Beberapa pelatihan yang dilaksanakan baik oleh pengelola KEK Mandalika maupun dari Kecamatan telah diiikuti oleh beberapa anggota kelompok termasuk pelatihan pembuatan kerupuk. Kerupuk yang dilatihkan adalah kerupuk ikan yang membutuhkan penjemuran sebelum digoreng.

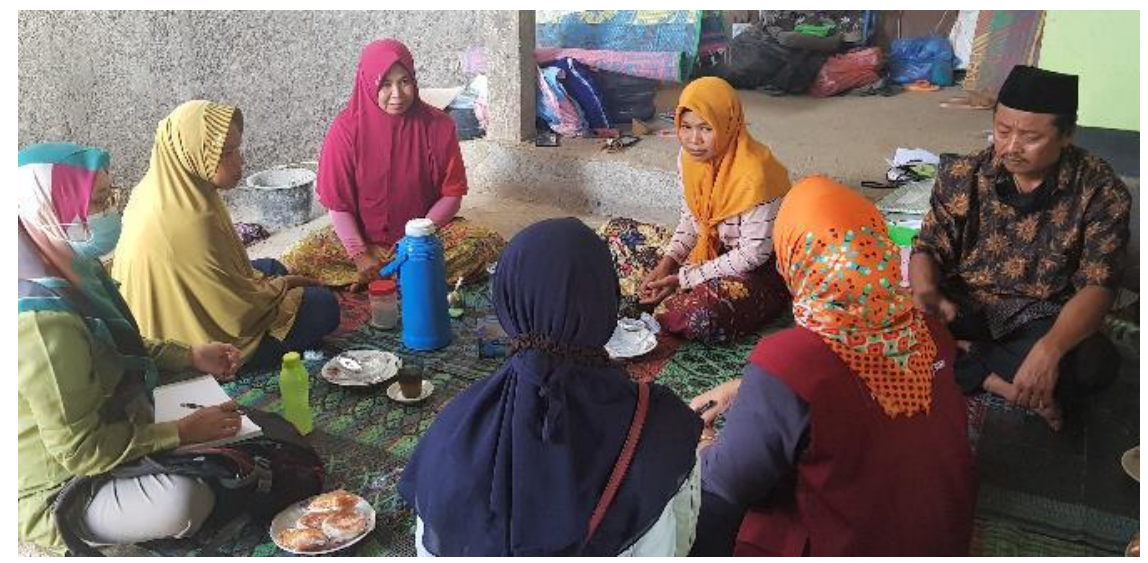

Gambar 2. Diskusi dengan calon peserta pelatihan yang difasilitasi oleh Sekretaris Desa Mertak.

Pada pertemuan tersebut, tim pengabdian menawarkan untuk memberikan perlatihan kerupuk ikan tanpa penjemuran, yang biasa disebut amplang, yang disambut baik oleh ibu-ibu calon peserta. Menurut asumsi mereka, metode pembuatan kerupuk tanpa penjemuran lebih baik karena hasilnya bisa langsung dinikmati.

Selain produk olahan, pertemuan tersebut juga membahas lokasi pelaksanaan pelatihan. Beberapa pilihan yang ditawarkan adalah kantor Desa Mertak, Rumah Sekdes, dan rumah warga calon peserta pelatihan. Melalui musyawarah diputuskan untuk melakukan di rumah warga calon peserta karena dianggap lebih representative. Karena terletak di jalan poros, maka lebih mudah dijangkau oleh peserta. Selain itu, ketersediaan air bersih dan alat-alat pendukung akan lebih mudah dimobilisasi. 
Setelah disepakati jenis produk olahan yang akan dipraktekkan bersama dengan peserta, maka persiapan selanjutnya adalah uji coba resep. Beberapa resep telah dikumpulkan dan sudah pernah dbuat sebelumnya, namun untuk memastikan resep yang akan diguanakan dalam pelatihan dilakukan kembali ujicoba. Resep yang dipilih adalah yang prosedurnya mudah diikuti dan dilakukan oleh peserta pelatihan.

\section{Tahap Pelaksanaan}

Pelaksanaan kegiatan pelatihan diawali dengan memberikan motivasi kepada peserta pelatihan untuk membuat produk olahan perikanan. Peserta juga diberikan penjelasan mengenai jenisjenis ikan yang dapat dijadikan bahan baku produk olahan ikan. Selain itu, dijelaskan pula mengenai peluang yang bisa dimanfaatkan oleh masyarakat Desa Mertak dengan adanya KEK Mandalika. Karena Desa Mertak termasuk desa penyangga, maka penduduk setempat akan mempunyai pasar yang luas untuk memasarkan produk mereka.

Setelah itu, dimulai kegiatan praktek pengolahan. Materi yang disampaikan dalam pelatihan sebelum dilakukan praktek pembuatan kerupuk ikan adalah :1) cara memilih bahan baku, 2) alat dan bahan yang akan digunakan, 3) langkah-langkah pembuatan kerupuk ikan.

Pada pinsipnya semua jenis ikan, baik ikan pelagis maupun demersal dapat digunakan sebagai bahan baku kerupuk ikan. Namun ikan harus dipastikan dalam kondisi segar. Ciri-ciri ikan segar antara lain mata jernih, mata cembung, insang merah segar, daging kenyal dan beraroma khas ikan (Riyantono, Abida and Farid, 2009; Tamuu, Marsuci and Dali, 2014; Fitriyah, Syauqy and Susilo, 2020).

Namun demikian, pada saat pelatihan disampaikan bahwa bahan baku yang pembuatan kerupuk sebaiknya ikan yang mempunyai daging yang mudah dipisahkan dari tulang dan kulit, daging tidak berwarna hitam dan mempunyai harga yang tidak mahal dan mudah didapatkan. Oleh karena itu, maka meskipun ikan tenggiri merupakan jenis ikan yang banyak digunakan sebagai bahan baku olahan ikan, baik kerupuk maupun bakso, namun tim pengabdian tidak merekomendasikan untuk menggunakan jenis ikan tersebut karena mempunyai harga yang mahal (Hakim, Anna and Junianto, 2014; Sobari and Febrianto, 2017).

Untuk membuat kerupuk diperlukan beberapa alat diantaranya pencincang daging, timbangan, sendok ukur, talenan, baskom, pengaduk, wajan dan kompor. Yang dijelaskan lebih detail ke peserta adalah alat pencincang daging dan alat ukur. Alat pencincang daging baik yang elektrik seperti food processor dan chopper maupun yang manual seperti pelumat daging ataupun cobek dapat digunakan dalam pembuatan kerupuk. Alat tersebut dapat dipilih sesuai dengan ketersediaannya selama berfungsi dengan baik.

Peserta pelatihan juga dijelaskan mengenai pentingnya menggunakan alat ukur seperti timbangan dan sendok ukur. Hal ini dimaksudkan agar bahan-bahan yang digunakan setiap membuat kerupuk sesuai dan sama takarannya sehingga rasa dan mutu kerupuk tetap sama.

Pembuatan kerupuk ikan melalui langkah-langkah sebagai berikut : 1) peserta diminta untuk menghaluskan ikan yang sudah difillet dan bersih dari kulit dan tulang, 2) mengaduk telur, gula, garam, dan bumbu dengan takaran sesuai resep yang digunakan, 3) mencampur adoanan telur dan daging ikan yang telah dihaluskan sampai rata, 4) memasukkan bahan pengembang dan tepung kanji ke dalam adonan, 5) membentuk adonan kerupuk, 6) menggoreng adonan kerupuk yang sudah dibentuk. 


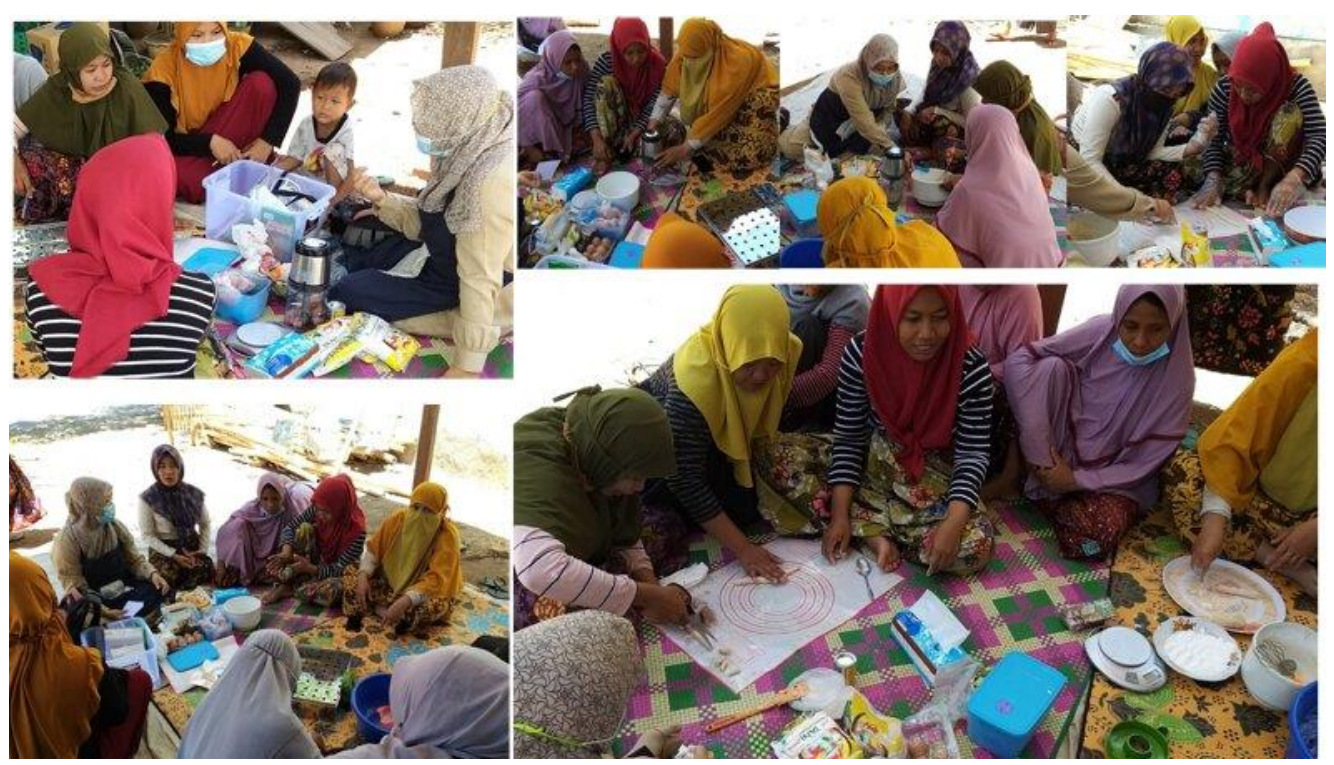

Gambar 3. Praktek Pembuatan Kerupuk Ikan, mulai dari pengenalan alat dan bahan sampai membentuk adonan kerupuk

Setiap langkah-langkah tersebut dijelaskan secara detail maksud, tujuan dan hal-hal yang perlu diperhatikan agar hasil yang diperoleh sesuai dengan harapan. Misalnya, pada saat menghaluskan daging ikan perlu dijaga suhunya agar tetap dalam kondisi dingin sehingga perlu dilakukan secara cepat. Begitu juga dengan cara penggorengan dijelaskan secara detail karena dapat menentukan hasil akhir produk. Teknik penggorengan yang dilakukan adalah memulai dengan minyak dingin, kemudian menggunakan api besar sampai adonan kerupuk mengembang dan mengapung, setelah itu menggunakan api kecil

sampai kerupuk benar-benar matang dan renyah.

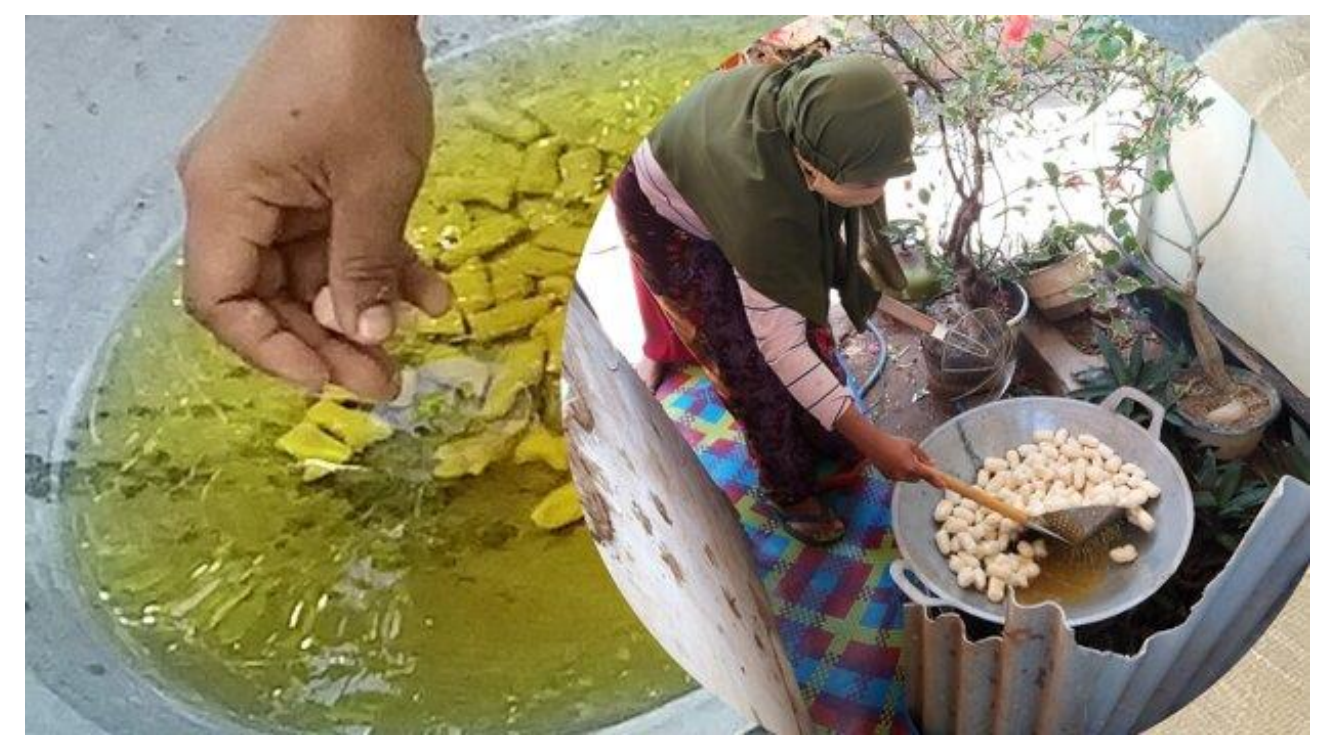

Gambar 4. Proses Penggorengan, dimulai dari minyak dingin kemudian minyak dipanaskan dengan api besar sampai adonan kerupuk mengapung dan mengembang dan dilanjutkan dengan api kecil sampai kerupuk matang. 
Selain cara pembuatan kerupuk, peserta juga diajarkan mengenai cara pengemasan apabila akan dijual secara umum. Materi ini dimulai dengan menentukan secara bersama-sama merk yang akan digunakan. Dalam simulasi tersebut, disepakati untuk membuat merk 'keripik-Q kerupuk ikan'. Selain itu peserta dijelaskan informasi yang wajib ada di label kemasan seperti nama produk, bahanbahan yang digunakan, berat produk per kemasan, ijin edar, nama dan alamat produsen, waktu kadaluarsa, dan kode (tanggal) produksi.

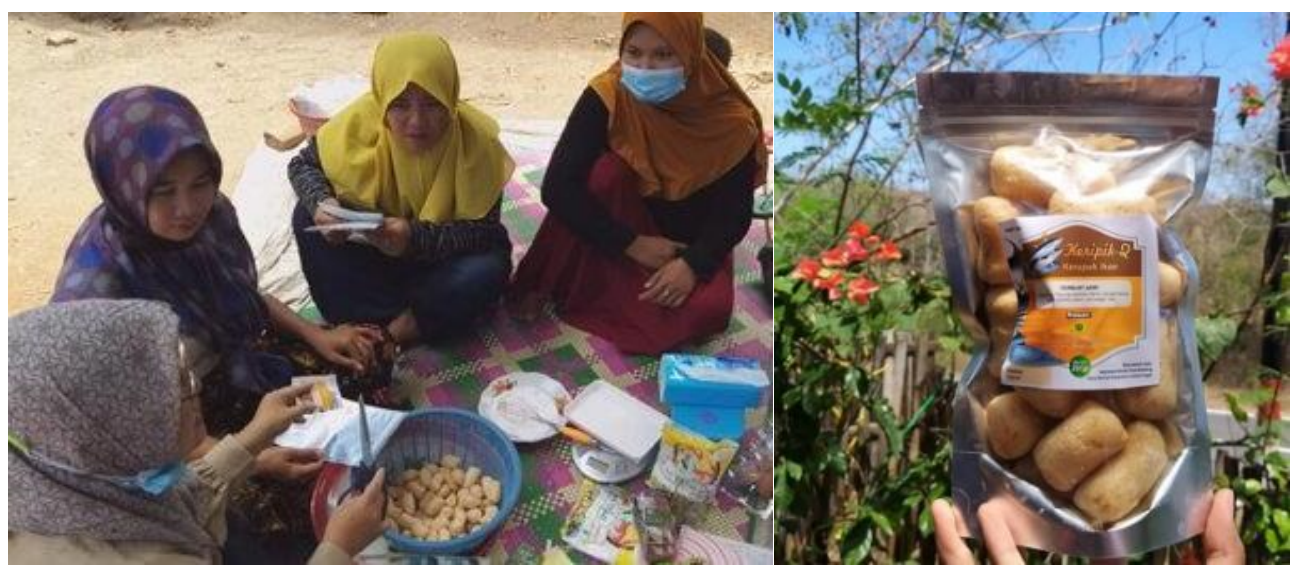

Gambar 5. Peserta juga diberikan materi mengenai pengemasan produk dan contoh kemasan

Seluruh proses kegaitan pelatihan dilakukan secara partisipatif. Peserta diberikan contoh dan kemudian langsung dipraktekkan. Hal ini dimaksudkan agar peserta bisa melakukan dan mengingat langkah-langkah dalam pembuatan produk. Peserta juga diberikan kesempatan untuk berkreasi dalam hal menentukan bentuk dan ukuran kerupuk agar mereka dapat menilai sendiri hasil pekerjaan mereka.

\section{Tahap Evaluasi}

Hasil wawancara dengan peserta di akhir kegiatan pelatihan diketahui bahwa peserta sangat puas dengan kerupuk yang mereka hasilkan. Hal ini juga diperlihatkan pada saat kerupuk digoreng. Mereka sangat antusias melihat kerupuk bisa mengembang dengan baik seperti kerupuk-kerupuk yang selama ini dijual. Peserta juga menyatakan bahwa rasa kerupuk sudah enak dan sesuai dengan selera mereka.

Peserta juga mengaku bahwa mereka sudah mampu membuat kerupuk sesuai dengan materi yang telah mereka dapatkan. Namun demikian, hasil evaluasi secara daring melalui whatsup group setelah 2 bulan dari waktu pelatihan diketahui bahwa belum ada peserta yang pernah membuat kembali kerupuk ikan. Hasil evaluasi tidak menemukan alasan spesifik kecuali peserta merasa belum punya waktu luang.

\section{KESIMPULAN DAN SARAN}

Berdasarkan kegiatan yang telah dilakukan maka dapat disimpulkan bahwa peserta pelatihan mempunyai antusiasme dalam megikuti pelatihan dan merasa puas dengan produk yang dilatihkan. Keterampilan peserta dalam membuat produk olahan ikan bertambah. Namun demikian, masih diperlukan pendampingan lebih lanjut agar keterampilan yang sudah dimiliki dapat dijadikan peluang usaha. 


\section{UCAPAN TERIMA KASIH}

Kegiatan pengabdian kepada masyarakat dilakukan menggunakan dana PNBP Universitas Mataram tahun anggaran 2019/2020. Penulis mengucapkan terima kasih kepada ketua dan seluruh staf Lembaga Penelitian dan Pengabdian Kepada Masyarakat (LPPM) Universitas Mataram, dan Tim BP3F Fakultas Pertanian yang telah memilih proposal kami untuk didanai. Kami juga mengucapkan terima kasih kepada Sekretaris Desa Mertak dan seluruh ibu-ibu peserta pelatihan atas bantuan dan kerjasamanya selama kegiatan pengabdian dilaksanakan.

\section{DAFTAR PUSTAKA}

Aji, R. R., Pramono, R. W. D. and Rahmi, D. H. (2018) 'Kontribusi Sektor Pariwisata Terhadap Ekonomi Wilayah Di Provinsi Jawa Timur', Jurnal Planoearth, 3(2), p. 57. doi: 10.31764/jpe.v3i2.600.

Amir, A., Sukarno, T. D. and Fauzi, R. (2020) 'Identifikasi Potensi dan Status Pengembangan Desa Wisata di Kabupaten Lombok Tengah, Nusa Tenggara Barat', Journal of Regional and Rural Development Planning, 4(2), pp. 84-98. doi: DOI: http://dx.doi.org/10.29244/jp2wd.2020.4.2.84-98.

Faizah, R., Sadiyah, L. and Aisyah, A. (2020) 'Struktur Komunitas dan Preferensi Habitat Ikan Karang pada Terumbu Buatan di Teluk Awang dan Teluk Bumbang, Pulau Lombok', Oseanologi dan Limnologi di Indonesia, 5(1), p. 61. doi: 10.14203/oldi.2020.v5i1.202.

Fitriyah, H., Syauqy, D. and Susilo, F. A. (2020) 'Deteksi Kesegaran Ikan Tongkol (Euthynnus Affinis) secara Otomatis Berdasarkan Citra Mata Menggunakan Binary Similarity', Jurnal Teknologi Informasi dan Ilmu Komputer. doi: 10.25126/jtiik.2020753839.

Hakim, L. L., Anna, Z. and Junianto, J. (2014) 'Analisis Bioekonomi Sumber Daya Ikan Tenggiri (Scomberomorus commerson) Di Perairan Kabupaten Indramayu Jawa Barat)', Jurnal Kebijakan Sosial Ekonomi Kelautan dan Perikanan. doi: 10.15578/jksekp.v4i2.599.

Ikhsan, M., Mardiana, M. and Setiawan, D. (2016) 'Multiplier Effect Industri Pariwisata Candi Muara Takus Terhadap Perekonomian Masyarakat Di Kecamatan Xii Koto Kampar Kabupaten Kampar', Jurnal Online Mahasiswa Fakultas Ekonomi Universitas Riau, 4(1), pp. 689-700.

ITDC (2020) ITDC Fokus Kembangkan The Nusa Dua Dan The Mandalika Menjadi Destinasi Wisata Unggulan Berkelas Internasional. Available at: https://www.itdc.co.id/press-release/itdcfokus-kembangkan-the-nusa-dua-dan-the-mandalika-menjadi-destinasi-wisata-unggulanberkelas-internasional-20200827 (Accessed: 20 November 2020).

Priyambodo, B., Jones, C. M. and Sammut, J. (2020) 'Assessment of the lobster puerulus (Panulirus homarus and Panulirus ornatus, Decapoda: Palinuridae) resource of Indonesia and its potential for sustainable harvest for aquaculture', Aquaculture. doi:

10.1016/j.aquaculture.2020.735563.

Riyantono, Abida, I. W. and Farid, A. (2009) 'Tingkat Ketahanan Kesegaran Ikan Mas (Cyprinus carpio) Menggunakan Asap Cair', Jurnal Kelautan.

Sobari, M. P. and Febrianto, A. (2017) 'Kajian Bio-Teknik Pemanfaatan Sumberdaya Ikan Tenggiri Dan Distribusi Pemasarannya Di Kabupaten Bangka', Jurnal Teknologi Perikanan dan Kelautan. doi: 10.24319/jtpk.1.15-29.

Tamuu, H., Marsuci, R. and Dali, F. A. (2014) 'Mutu Organoleptik dan Mikrobiologis Ikan Kembung Segar dengan Penggunaan Larutan Lengkuas Merah', Jurnal Ilmiah Perikanan dan Kelautan. 